\title{
Cathodic protection modelling of a propeller shaft
} 3 7 8

\author{
Sergio Lorenzi ${ }^{\mathrm{a}}$, Tommaso Pastore ${ }^{\mathrm{a}}$, Tiziano Bellezze ${ }^{\mathrm{b}, *}$, Romeo Fratesi $^{\mathrm{b}}$
}

${ }^{\text {a }}$ University of Bergamo, Department of Engineering and Applied Sciences

Viale Marconi 5, 24044 Dalmine (BG) - ITALY

bUniversità Politecnica delle Marche, Department of Materials, Environmental Sciences and Urban Planning Via Brecce Bianche, 60131 Ancona - ITALY

(

4
5

\section{6}

a Sergio Lorenzi: Tel. +39 035 2052052, Fax +39 035 2052043, e-mail sergio.lorenzi@unibg.it aTommaso Pastore: Tel. +39 035 2052316, Fax +39 035 2052043, e-mail tommaso.pastore@ @nibg.it b, ${ }^{*}$ Tiziano Bellezze: corresponding author, Tel. +39 071 2204413, Fax +39 0712810327 , 2 t.bellezze@univpm.it

3 bomeo Fratesi: Tel. +39 071 2204741, Fax +39 071 2810327, e-mail r.fratesi@ univpm.it 24 


\section{Abstract}

2 Current and potential distributions on a stainless steel propeller shaft protected by galvanic anodes

3 were investigated by means of Finite Element Method (FEM) modelling. The effect of seawater

4 flow and shaft rotation was evaluated. The results of simulations are compared with experimental

5 measurements performed on steady shaft in natural seawater. Modest polarization can be noticed in

6 all operating conditions, not sufficient for preventing biofilm action on localized corrosion

7 initiation. Only in stagnant conditions, without any water renewal, the consumption of oxygen leads

8 to an appreciable potential decreasing to match the limits of normal protection indicated in the

9 European standards.

11 Keywords: A. carbon steel, A. stainless steel, B. modelling studies, B. polarization, C. cathodic

12 protection, C. pitting corrosion.

\section{Introduction}

15 Cathodic protection is the main technique for preventing corrosion on external surfaces of carbon steel parts in the submerged zones of ships, harbour installations and offshore structures that operate in direct contact with seawater. Such protection is frequently used also for internal parts of marine

18 equipment in which seawater flows - such as tanks, filters, pumps, valves - even if made of

19 corrosion resistant alloy. The combination of cathodic protection and corrosion resistant alloys may

20 be a convenient solution. The cathodic protection of stainless steel can avoid localized corrosion

21 induced by chlorides and makes possible the utilization of alloys with lower contents of chromium

22 and molybdenum compared to the levels needed for the corrosion resistance in seawater, thus

23 allowing the use of less expensive steels.

24 This work deals with feasibility study of a galvanic cathodic protection system of a ship propeller 25 shaft-stern tube assembly made of stainless steels, by galvanic carbon steel anodes. Experimental 
1 studies using both impressed current method and sacrificial galvanic anodes of the cathodic

2 protection of the propeller system considered in this work are described in previous papers [1-3].

3 This work reports on a study of current and potential distributions through a simulation by Finite

4 Element Model (FEM) under more general conditions of exposure, covering longitudinal flow of 5 water between shaft and stern tube and shaft rotation.

\section{The apparatus} The apparatus studied in this work is a propeller system of a ship (Fig. 1) equipped by a stern tube

9 made of AISI 304 stainless steel and a shaft of AISI 630 stainless steel, better known as 17-4 PH.

10 The chemical composition of the steels is reported in Table 1.

11 Stainless steels are traditionally used for these applications, where also other stainless steels are

12 used, such as AISI 303 and AISI 316, or more recent alloys including duplex stainless steels

$13(22 \mathrm{Cr} 5 \mathrm{Ni})$ and super duplex $(25 \mathrm{Cr} 7 \mathrm{Ni})$, as valid alternative to non-ferrous alloys (i.e. copper-nickel

14 alloy Monel K-500).

15 In seawater, stainless steels are susceptible to pitting and crevice corrosion. The insurgence of such

16 localized corrosion forms can lead to premature failures of propeller shaft, because pits act as

17 preferential sites for fatigue initiation. The resistance to localized attack depends on alloy

18 composition. Chromium and molybdenum contents and nitrogen content - for the most recent

19 austenitic and duplex stainless steels - enhance it.

20 The Pitting Resistance Equivalent Number (PREN) is usually adopted in order estimate the relative 21 pitting corrosion resistance of stainless steels in chloride-containing environments. Higher PREN

22 values indicate greater corrosion resistance. The PREN is defined as 
1 In seawater, which has a typical amount of chlorides of about $19000 \mathrm{ppm}$, and under the most

2 critical exposure for localized attack initiation, that is in stagnant conditions, a PREN over 40 is necessary to achieve complete corrosion resistance. The risk reduces in flowing water and it

4 becomes nil in turbulent flow constantly over a threshold, commonly assumed at about $1.5 \mathrm{~m} / \mathrm{s}$ in

5 pipes, for AISI 316 stainless steel, having PREN 25-27.

6 The pitting initiates in oxidizing chloride containing solutions, such as aerated seawater, under

7 exposure conditions giving free corrosion potentials higher than the pitting potential $\left(E_{\mathrm{pit}}\right)$.

\subsection{Cathodic protection of stainless steel propeller system}

10 Generally speaking, cathodic protection is able to prevent the localized corrosion. The main effect

11 consists in the lowering of the potential. Two situations can arise: the cathodic protection is applied

12 since early stage of exposure, before any corrosion initiation, or later, once localized attack initiates.

13 The attack cannot initiate in any case if cathodic protection is applied since early stage and

14 polarization is sufficient to maintain the potential stably under the pitting potential. Thus, the

15 protection potential matches with the pitting potential and it depends on the PREN of the alloy and

16 environmental characteristics, primarily chloride concentration, temperature and $\mathrm{pH}$.

17 The cathodic protection applied after localized corrosion initiation requires polarizations enough to 18 reach the re-passivation potential $\left(E_{\text {rep }}\right)$, which is typically $200-300 \mathrm{mV}$ lower than the pitting

19 potential. Such pronounced polarization is needed because the modifications induced by the 20 mechanism of the occluded cell produces strong acidification and considerable increase in the 21 chloride concentration inside the pit. Such modifications contrast the re-formation of passive film 22 on the active areas of the localized attack. As a consequence, the protection potential for stopping 23 corrosion attack becomes equal to the re-passivation potential. Fig. 2 shows the two different 24 conditions for cathodic protection.

25 The European standard EN ISO 15589-2 [4] gives the protection conditions for stainless steels with respect to the composition of the alloy and its PREN. It suggests a protection potential of $-0.3 \mathrm{~V}$ vs 
1 SCE for austenitic stainless steels with PREN greater than 40. For steels with lower PREN values,

2 the potential decreases to $-0.5 \mathrm{~V}$ vs SCE. This limit is also considered for martensitic and duplex

3 stainless steels. A different limit, equal to $-0.6 \mathrm{~V}$ vs SCE, is reported in the EN 12473 [5].

4 As far as the over-protection conditions are considered, the austenitic stainless steels are fully

5 compatible with the cathodic protection and thus they have the normal limit of $-1.1 \mathrm{~V}$ vs SCE

6 assumed for steels not susceptible to hydrogen embrittlement. However, other type of stainless steel

7 with different microstructures may be susceptible to hydrogen embrittlement, depending on their

8 mechanical strength and the level of applied loading. In the matter of hydrogen embrittlement risk,

9 the susceptibility of 17-4 PH stainless steels after ageing at low temperature - in order to achieve

10 high strength - is known since the '70s [6]. Thus, in accordance with the mentioned standards for

11 avoiding the risk of ruptures on susceptible alloys, the potential should never decrease below $-0.8 \mathrm{~V}$

12 vs SCE.

13 An intrinsically safe solution for avoiding any risk on susceptible alloys is the use of galvanic

14 carbon steel anodes (Fig. 1). Actually, the galvanic coupling with these anodes limits the

15 polarization to the free corrosion potential of the carbon steel, hence at polarization level much

16 nobler than the critical limit for the overprotection.

\section{Theoretical background}

\subsection{The numerical model}

20 The current and potential distributions were studied by means of commercial finite element

21 software.

22 The interspace between shaft and stern tube was discretized by using a three-dimensional model, by

$232 \cdot 10^{5}$ tetragonal elements with dimension in the range of $0.5-50 \mathrm{~mm}$, refined near the anode areas.

24 Two carbon steel anodes are placed on a same generatrix of the stern tube (Fig. 1). The anodes are two steel bars of $35 \mathrm{~mm}$ diameter that protrude from the tube wall up to half of the interspace. 


\subsection{Field equations and boundary conditions}

2 Assuming negligible the concentration gradients, the distribution of the potential $(\phi)$ and current 3 density (i) in the water is governed by Laplace's equation (Eq. 2) and Ohm's law (Eq. 3). It can be 4 calculated, knowing the electrical conductivity of the water $(k)[7,8]$

$$
\begin{gathered}
\nabla^{2} \phi=0 \\
i=-k \operatorname{grad} \phi
\end{gathered}
$$

The solution is obtained by solving the two equations within the electrolyte domain (i.e. the water) by imposing the boundary conditions that describe on the surface the relation between flowing current density and potential. On insulating surfaces, which do not exchange current, the boundary condition is to set a null current density in the normal direction to the surface $\left(i_{\mathrm{n}}\right)$ that is equivalent to set at zero the gradient of potential over this direction:

$$
i_{\mathrm{n}}=0 \quad \text { equivalent to } \quad \frac{\mathrm{d} \phi}{\mathrm{d} n}=0
$$

On the surface of the structure to be protected (cathode) and anode, the current density exchanged through the surface is a function of the potential of the metal in the electrolyte, $E_{\mathrm{c}}$ and $E_{\mathrm{a}}$ respectively. The boundary conditions match with the polarization curves of the materials.

The potential distribution in the domain describes the ohmic drop in the water between two generic points $\left(\Delta \phi_{\mathrm{ij}}=\phi_{1}-\phi_{\mathrm{j}}\right)$. The potential $(E)$ assessed by a reference electrode placed in the electrolyte in a generic position, at some distance from the cathode, is given by the algebraic sum of the potential of the cathode (by definition, measured with respect to the reference electrode placed in the electrolyte immediately adjacent to the cathode itself) and the ohmic drop in the electrolyte ( $\left.\Delta \phi_{\mathrm{ic}}\right)$ between the generic point and the cathode

$$
E_{\mathrm{i}}=\Delta \phi_{\mathrm{ic}}-E_{\mathrm{c}}
$$

Therefore, by a change of variables, Eqs. 2 and 3 govern also the distribution of the potential $E$. Considering that the ohmic drop $\left(\Delta \phi_{\mathrm{ic}}\right)$ vanishes at the cathode, as it has been defined, the boundary conditions on the protected structure become 


$$
E=-E_{\mathrm{c}}
$$

2 In the case of impressed current cathodic protection system, the boundary conditions on the anode is related to the anode potential through the following relationship derived by considering the feeding

4 voltage (V) of DC power supplier and the ohmic drops $(I R)$ in the cables,

$$
E=-E_{a}+V-I R
$$

6 With galvanic anodes directly connected to the cathode without any external electrical power supply $(V=0)$, the ohmic drops in the connectors is negligible. The Eq. 7 becomes

$$
E=-E_{\mathrm{a}}
$$

\subsection{The expression of polarization curves}

11 The polarization curves of the materials define the boundary conditions. Several papers reported the mathematical equations defining non linear boundary conditions based on polarization curves of steel, especially applied to boundary elements method [9-15] and finite element methods [16]. The mathematical equations of the polarization curves adopted for cathodic protection modelling in seawater are reported by several authors [17,18]. In previous works $[19,20]$, the behaviour of a HSLA steel grade X65 was studied in synthetic seawater and then used for modelling current and potential distributions on offshore structures [21,22], underground tanks [23] and for evaluating internal electrical interference on insulating joints of pipelines for water transport [24].

19 The polarization curve is the sum of the anodic and cathodic processes which can occur on the metal surface. Its description is based on the Butler and Volmer equation for electrochemical

21 processes that are not limited by transport phenomena. For the oxygen reduction at the typical potential of carbon steel corrosion, the limiting current density can be estimated from mass transport coefficient, which can be estimated by dimensionless relationship derived by fluid

24 dynamics. Selman and Tobias [25] describe empirical correlations for mass transfer in a large variety of geometries. 
1 The processes involved in corrosion and cathodic protection of steel are the anodic process of metal

2 oxidation (corresponding to the current density $i_{\mathrm{a}}$ ), the cathodic process of reduction of dissolved

3 oxygen in the water $\left(i_{\mathrm{c}, \mathrm{O}_{2}}\right)$ and the cathodic process of hydrogen evolution from water reduction

$4 \quad\left(i_{\mathrm{c}, \mathrm{H}}\right)$. The total current density $(i)$ flowing through the metallic surfaces is the sum of these three

5 contribution, according to the following equation (negative sign for cathodic currents)

$$
i=i_{\mathrm{a}}-i_{\mathrm{c}, \mathrm{O}_{2}}-i_{\mathrm{c}, \mathrm{H}}
$$

7 On the submerged part of marine structures, the formation of calcareous scale gradually reduces the current required for the protection. A thick compact scale is a barrier to the oxygen access to the

9 metal surface and decreases the exposed surface. This phenomena plays an important role during structure polarization and is fundamental for effectiveness of cathodic polarization [26,27]. As a consequence, cathodic protection modelling has to take into account time-dependent boundary conditions. Since the 80 s, empiric models were proposed for describing time variation of polarization curves $[17,18,20]$. Recently, further models were proposed to explain precipitation and growth mechanisms $[28,29]$. Nevertheless, only the initial stages of polarization - in absence of relevant growing of calcareous deposit on the protected surface - are considered in this paper. The reason of such an approach is based on the specific nature of the cathodic protection of stainless steels. Because the absence of calcareous scale gives very uneven current distribution, the initial polarization period is critical especially in complex geometries. Cathodic protection could not prevent the risk of localized corrosion initiation on the areas where the current cannot penetrate. The early initiation of the attack then makes difficult to reach a complete corrosion protection, because higher polarization is required to re-passivate corroded areas, in zones where the penetration of currents is indeed limited due to the geometry.

24 Furthermore, cathodic protection of stainless steels is applied at cathodic current densities lower than the usual values adopted for carbon steel structures. Consequently, limited alkalinisation on the protected surface occurs, with a slower kinetic of scale growth. The deposit forms over long time, 
1 on surfaces where a fouling layer is already developing, which reduces calcareous scale adhesion

2 and make it easily removable by turbulent flow. Johnsen and Bardal [30] reported the absence of

3 scale formation during potentiostatic tests carried out in natural seawater, on different types of

4 stainless steel, for water flow rates in the range $0.5-1.2 \mathrm{~m} / \mathrm{s}$, even for high protection current

5 density. Long periods of scale formation are not helpful to prevent the localized corrosion initiation

6 on complex geometries.

\subsubsection{Anodic process of dissolution}

9 Because the active behaviour in seawater, the anodic characteristic of the carbon steel $\left(i_{\mathrm{a}, \mathrm{Fe}}\right)$ as a

10 function of potential $E$ can be expressed by Tafel law

$$
i_{\mathrm{a}, \mathrm{Fe}}=i_{0, \mathrm{Fe}} \exp \left(\frac{E-E_{\mathrm{eq}, \mathrm{Fe}}}{B_{\mathrm{Fe}}}\right)
$$

where $i_{0, \mathrm{Fe}}, E_{\mathrm{eq}, \mathrm{Fe}}$ and $B_{F e}$ are respectively the exchange current density, the equilibrium potential and the Tafel constant on a natural logarithm scale corresponding to carbon steel.

14 Stainless steel has more complex behaviour, due its passive nature. At the $\mathrm{pH}$ of seawater, the

anodic process rapidly achieves passive state due to the formation of protective chromium oxide, without a relevant activity peak. From the equilibrium potential, very close to that of carbon steel, the current density reach the passivity current density $\left(i_{\mathrm{a}, \mathrm{p}}\right)$. The anodic curves of stainless steel $\left(i_{\mathrm{a}, \text { inox }}\right)$ can be expressed by modifying Eq. 10 with an asymptotic approach to the passivity current density, through the relationship

$$
\frac{1}{i_{\mathrm{a}, \text { inox }}}=\frac{1}{i_{\mathrm{a}, \mathrm{Fe}}}+\frac{1}{i_{\mathrm{a}, \mathrm{p}}}
$$

\subsubsection{Oxygen cathodic process}

Both charge transfer and mass transfer limit the current density for oxygen reduction. The total current density $\left(i_{c, O_{2}}\right)$ is given by 


$$
\frac{1}{i_{\mathrm{c}, \mathrm{O}_{2}}}=\frac{1}{i_{\mathrm{ctc}, \mathrm{O}_{2}}}+\frac{1}{i_{\mathrm{lim}, \mathrm{O}_{2}}}
$$

2 where $i_{\mathrm{ctc}, \mathrm{O}_{2}}$ and $i_{\mathrm{lim}, \mathrm{O}_{2}}$ are charge transfer current density and mass transfer limiting current

3 density, respectively.

4 Charge transfer current density as a function of potential $E$ is given by the following law

$$
i_{\mathrm{ctc}, \mathrm{O}_{2}}=i_{0, \mathrm{O}_{2}} \exp \left(\frac{E-E_{\mathrm{eq}, \mathrm{O}_{2}}}{B_{\mathrm{O}_{2}}}\right)
$$

6 where $i_{0, O_{2}}, E_{e q, O_{2}}$ and $B_{O_{2}}$ are respectively the exchange current density, the equilibrium potential and the Tafel constant on a natural logarithm scale corresponding to oxygen. The charge transfer term defines the free corrosion potential of passive stainless steels. In natural

9 seawater, the biofilm settlement depolarizes the oxygen reduction reaction. This effect - described

10 by Mollica and Trevis since the late 80s [31] - produces a shift of the free corrosion potential of

11 passive alloys toward noble potentials (ennoblement) during early periods of exposure. Faimali et al 12 [32] reported corrosion potential increase of 350-400 $\mathrm{mV}$ for super austenitic steels with high

13 resistance to localized corrosion. On stainless steels with lower chromium and molybdenum content 14 (lower PREN), such an increase leads to the initiation of localized corrosion after free corrosion 15 potential reaches the pitting potential. After the initiation, the anodic curve of stainless steel is no 16 longer described by Eq. 11. The mechanisms by which the biofilm causes "cathodic depolarisation" were discussed in the works of Beech and Sunner [33], Little et al [34] and Landoulsi et al [35]. To consider this effect on the polarization curve, it is conveniently to modify Eq. 13 in terms of free

19 corrosion potential $\left(E_{\text {cor,inox }}\right)$ and corrosion current density $\left(i_{\text {cor,inox }}\right)$. In passive conditions, the

20 corrosion current density is equal to the passive current density $\left(i_{\text {cor, }, \text { inox }}=i_{\mathrm{a}, \mathrm{p}}\right)$

$$
i_{\mathrm{ctc}, \mathrm{O}_{2}}=i_{\mathrm{a}, \mathrm{p}} \exp \left(\frac{E-E_{\text {cor,inox }}}{B_{\mathrm{O}_{2}}}\right)
$$

22 In the absence of deposits covering the surface - which can reduce the access of oxygen - the fluid 23 dynamic conditions at the shaft/stern tube surfaces define the limiting current density. The mass 
1 transport of oxygen towards the steel surfaces is determined by the shaft rotation and water flow in

2 the annulus.

3 For modelling the propeller system considered in this work, two different situations are assumed,

4 one related with anchored or moored ship in harbour, the other with rotating propeller shaft during

5 ship navigation.

6 In the first case, water has a longitudinal flow in the annulus or is stagnant. These conditions were

7 those considered during experimental studies for assessing current and potential distributions

8 directly on the propeller system [2].

9 For mass transfer in turbulent flow in an annulus, Lin et al [36] proposed a relationship in terms of 10 dimensionless numbers of Sherwood (Sh), Reynolds $(R e)$ and Schmidt $(S c)$, valid for $R e$ between $11 \quad 2100$ and 30000

$$
S h=0.023 R e^{0.8} S c^{\frac{1}{3}}
$$

13 Table 2 summarizes the definitions for parameters and dimensionless numbers used in the

14 relationships. The oxygen mass transfer coefficient $(k)$ is calculated from the Sherwood number.

15 Then the limiting current density $\left(i_{\mathrm{lim}, \mathrm{O}_{2}}\right)$ can be estimated from the concentration of oxygen $\left(C_{\mathrm{O}_{2}}\right)$ 16 in the water

$$
i_{\mathrm{lim}, \mathrm{O}_{2}}=4 F k C_{\mathrm{O}_{2}}
$$

18 where $\mathrm{F}$ is the Faraday's constant.

19 During ship navigation, in the hypothesis of the relative speed between metallic walls and water is 20 determined only by the shaft rotation and water movement in the longitudinal direction is 21 negligible, the oxygen limiting current density can assessed by equations for the turbulent Couette 22 flow between a rotating inner cylinder and an outer coaxial and stationary cylinder proposed by 23 Eisemberg [37] Gabe and Robinson [38,39], Kishinevskii et al [40]. In particular, the equation of 24 Eisemberg is assumed for $1000<R e<100000,835<S c<11490,0.093<d_{\mathrm{i}} / d_{0}<0.83$

$$
S h=0.0791 R e^{0.7} S c^{0.356}
$$


1 Fig. 3 shows the variation of the limiting current density of oxygen estimated for the two situations,

2 in aerated water at $15{ }^{\circ} \mathrm{C}$, as a function of the shaft rotation speed and of the flow rate of

3 longitudinal flux (without shaft rotation), expressed as relative velocity between water and metallic

4 surface.

$6 \quad$ 3.3.3. Hydrogen cathodic process

7 The hydrogen evolution process from water reduction can be described by the expression of the corresponding cathodic current density $\left(i_{\mathrm{c}, \mathrm{H}}\right)$

$$
i_{\mathrm{c}, \mathrm{H}}=i_{0, \mathrm{H}} \exp \left(\frac{E-E_{\mathrm{eq}, \mathrm{H}}}{B_{\mathrm{H}}}\right)
$$

10 where $i_{0, \mathrm{H}}, E_{e q, \mathrm{H}}$ and $B_{\mathrm{H}}$ are respectively the exchange current density, the equilibrium potential

11 and the Tafel constant on a natural logarithm scale corresponding to hydrogen.

12 The $\mathrm{pH}$ influences the electrochemical kinetic to limited extent at $\mathrm{pH}$ less than 10 . At room

13 temperature, the slope on decimal logarithm scale is close to $120 \mathrm{mV} /$ decade and tends to increase

14 at high overvoltages [41,42].

15

\subsubsection{The overall curves}

17 The overall polarization curves $(i)$ for carbon steel and stainless steel are expressed by Eqs. 19 and

1820 (negative sign for cathodic currents): Eq. 19 is obtained combining Eqs. 10, 16 and 18 whereas

19 Eq. 20 is obtained combining the inverse of Eqs. 11 and 12 with Eq. 18. The active behaviour of

20 iron dissolution is expressed by the Eq. 10, which is transformed in Eq. 21 so as to use $i_{\mathrm{Fe}}$ pre-

21 exponential parameter published in previous works $[9,12]$ and reported in Table 3.

$$
i=i_{\mathrm{a}, \mathrm{Fe}}-i_{\mathrm{lim}, \mathrm{O}_{2}}-i_{\mathrm{c}, \mathrm{H}}
$$

$$
i=\frac{1}{\frac{1}{i_{\mathrm{a}, \mathrm{Fe}}}+\frac{1}{i_{\mathrm{a}, \mathrm{p}}}}-\frac{1}{\frac{1}{i_{\mathrm{ctc}, \mathrm{O}_{2}}}+\frac{1}{i_{\mathrm{lim}, \mathrm{O}_{2}}}}-i_{\mathrm{c}, \mathrm{H}}
$$

$$
i_{\mathrm{a}, \mathrm{Fe}}=i_{\mathrm{Fe}} \exp \left(\frac{E}{B_{\mathrm{Fe}}}\right)
$$


1 From the mentioned works, in addition to $i_{\mathrm{Fe}}, i_{\mathrm{a}, \mathrm{p}}$ and $i_{0, \mathrm{H}}$, also the Tafel " $b$ " constants on decimal

2 logarithm scale (Table 3) were used in Eqs. 19, 20 and $21\left(B_{S}=b_{S} / 2.3026\right.$ where $S$ is the oxidizing

3 or the reducing species).

$4 \quad$ Figs. 4 and 5 show the plots relative to Eqs. 19 and 20, respectively.

5 For comparison, Fig. 6 shows the anodic and cathodic potentiodynamic curves of 17-4PH stainless

6 steel in natural seawater reported by Bellezze et al [1,3]. The curves were obtained in stagnant

7 conditions, within one hour from the immersion of the specimen in the water. The anodic curves

8 show the initiation of pitting corrosion, with a clear hysteresis in the return curve. The pitting

9 potential is about $0.06 \mathrm{~V}$ vs. SCE, with the re-passivation potential at about $-0.03 \mathrm{~V}$ vs SCE.

11 4. Results and discussion

12 4.1. Validation of the model

13 In order to validate the model, the distributions derived by simulation were compared with

14 experimental measurements performed on stationary shaft, in aerated natural seawater, under

15 stagnant conditions or with $40 \mathrm{~L} / \mathrm{min}$ of longitudinal flow. The experimental setup is described by

16 Bellezze et al [2]. During the experimentation, the potential was measured by means of reference

17 electrodes placed at regular intervals on the stern tube in correspondence of the opposite generatrix

18 with respect to that where the anodes are placed (Fig. 1). The currents were measured by shunt

19 resistances between the anodes and the protected structure.

20 During modelling, it was assumed a temperature of $15^{\circ} \mathrm{C}$, a typical composition of seawater with

21 an electrical resistivity of $0.2 \Omega \mathrm{m}$ and a saturation concentration of dissolved oxygen (8 ppm). For

22 the definition of the boundary conditions on the stainless steel, the free corrosion potential $\left(E_{\text {cor,inox }}\right)$

23 was assumed equal to $0.078 \mathrm{~V}$ vs. SCE (Table 3), on the basis of experimental measurements at

24 early exposures. The same polarization curve is assumed for shaft and stern tube, despite the

25 propeller system is made of two different type of stainless steel. 
1 Fig. 7 shows the potential distribution in the annulus, at $40 \mathrm{~L} / \mathrm{min}$ of longitudinal flow. The

2 polarization is limited to the areas next to the anodes, thus denoting a poor penetration of protection

3 current both along the longitudinal direction and the circumference. The maximum polarization

4 near the anodes is about $0.4 \mathrm{~V}$ with respect to free corrosion potential, but it reduces to a few tens of

5 millivolts on the generatrix of the stern tube far from the anodes. The potential distribution is in

6 good agreement with the experimental data (Fig. 8).

\subsection{Simulation of distribution in stagnant water and stationary propeller shaft}

9 Fig. 9 and Fig. 10 compare the model results with experimental measurements performed at

10 different times with stagnant water, in closed annulus without any oxygen exchange. Because the

11 Eqs. 15 and 17 do not apply under these circumstances, for the initial limiting current density to be

12 introduced in Eqs. 19 and 20 it was assumed the value required for producing the same initial

13 galvanic current measured during experimental polarizing tests on the propeller system. Then, the

14 evolution of the polarization curves was estimated by considering the oxygen consumption and the

15 variation that it determines on the limiting current density (Eq. 16). The oxygen consumption by the

16 cathodic process leads to a decrease of the galvanic current exchanged between the anodes and the

17 structure and a considerable increase of the polarization, which brings the potential at about $-0.6 \mathrm{~V}$

18 vs SCE even in the zones far away from the anodes, after 70 hours (Fig. 11). For simplicity, it was

19 considered that the whole flowing current contributes to oxygen consumption, ignoring the

20 hydrogen cathodic process, because it only becomes important at very low potentials.

21 From the Eq. 16 and Faraday's law, the following relationship can be derived for describing time

22 evolution of limiting current

$$
\frac{\mathrm{d} i_{\lim , \mathrm{O}_{2}}}{\mathrm{~d} t}=-\frac{k}{V} I(t)
$$

where $V$ is the volume of water end $I(t)$ is the cathodic current flowing between anodes and structure.

Considering constant the mass transport coefficient $k$, it can be related with the initial values of 
oxygen concentration and limiting current density through Eq. 16. From these assumptions, the

2 following relationship can be written

$$
i_{\lim , \mathrm{O}_{2}}(t)=i_{\lim , \mathrm{O}_{2}}(0)-\frac{k}{V} \int_{0}^{t} I(\tau) d \tau
$$

4 Despite the approximations assumed for the mass transfer coefficient, the results allow a reliable

5 interpretation of the experimental data, which confirms the main effect due to the depletion of

6 oxygen concentration. Only once it becomes relevant, the polarization reaches the protection

7 potential of stainless steels (Figs. 10 and 11). This fact is evident after tens of hours, which is a relatively long time compared to the normal periods of ship in harbour, but much lower than the

9 periods of mooring of occasionally used yachts.

\section{4.3. Shaft rotation effect}

12 Fig. 12 and Fig. 13 show the results of simulations with rotating shaft. They show the distributions

13 along the generatrix of the shaft opposite to the anodes. The distributions are compared to the 14 stationary shaft, with $40 \mathrm{~L} / \mathrm{min}$ longitudinal flow. Rotational speeds of $5 \mathrm{~Hz}$ and $1 \mathrm{~Hz}$ have been 15 considered. The boundary conditions have been defined according to Eqs. 15, 17 and 20, by 16 considering the same transport conditions both on shaft and on stern tube, for simplicity.

17 Stationary conditions have been assumed without any polarization transients. Actually, the 18 polarization conditions in the zones close to the anodes are variable as a function of the rotation. In

19 the zones of the shaft facing to the anodes, each point of the circumference passes from high 20 polarization, when it is near the anode, to a low one, when it is in the opposite zone. In first 21 approximation, the cycle is that described in Fig. 14. Each point is subjected to a pulsed cathodic 22 protection with a frequency equal to the rotation of the shaft. The waveform of the current depends on the circumferential distribution. Only if the rotational frequency is low, the behaviour tend to the

24 stationary distribution described by the model (Figs. 12 and 13). The polarization changes as 25 frequency increases, producing minor fluctuations. 
1 Even with these limitations, however, the model is representative of the maximum possible

2 polarization in the most polarized zones and of the minimum polarized zones in remote positions,

3 where fluctuation becomes negligible.

4 The results of simulations indicate that the polarization reached by the cathodic protection system

5 considered in this work is poor with aerated water and longitudinal flow or rotating shaft. The

6 potential are far from protection potential indicated in the technical standards. Furthermore, as the

7 rotation speed increases, the increase of the current demand reduces the throwing power. Thereby,

8 the current density that reaches the back side of shaft -far away from the anodes- decreases as

9 shown in Fig. 13.

\section{4.4. Conditions of protection}

12 Except in stagnant water without renewal, all the other situations analysed do not show sufficient

13 polarization for achieving the protection potentials indicated by the technical standards on cathodic

14 protection. As far as these limits are taken into account, the propeller system cannot be considered

15 protected. Thus, only large zones are in conditions of moderate polarization during early exposure,

16 when calcareous scale deposit is not yet formed.

17 However, even if it is low, a polarization of tens of millivolts is able to lower the potential below

18 the value of pitting potential measured by the potentiodynamic tests (Fig. 6). Thus, although

19 limited, the polarization would seem to be able to prevent the initiation of localized corrosion, but

20 this interpretation is not reliable. The low polarizations estimated by simulations should be

21 interpreted as inadequate to prevent the risk of localized corrosion, according to the following

22 considerations.

23 First of all, there is an intrinsic difficulty for assessing the pitting potential from short-time

24 potentiodynamic tests. Secondly, it is important to consider that the localized attack mainly initiates

25 in crevice or under fouling deposits. Under these conditions, the critical potential is lower than the 26 pitting potential obtained on bare steel surface. 
1 Furthermore, biofilm growth can also play a crucial role. At usual temperatures found in seawater -

2 well below $40{ }^{\circ} \mathrm{C}$ - the biofilm modifies the cathodic process of oxygen. The bacteria activity raises

3 the exchange current density, thus reducing the activation overvoltage and producing the previously

4 described ennoblement [31]. The bacteria can also act under cathodic protection. Johnsen and

5 Bardal [30] explain the considerable increase of current demand at low cathodic polarizations

6 induced by biofilm phenomena. Such effect was observed in natural seawater on different types of

7 stainless steel. At very low cathodic current densities - typical of cathodic protection at moderate

8 polarizations - the potential is mainly determined by the activation overvoltage of the oxygen

9 reduction process, similarly to free corrosion conditions. Thus - on low polarized zones of the

10 structure - an increase of the exchange current density due to the presence of bacteria can also cause

11 an increase of the potential under cathodic protection. At protection potentials recommended by the

12 technical standards, this effect becomes negligible because the process of oxygen reduction is

13 mainly governed by the mass transport phenomena rather than charge transfer on the metal surface.

14 Such recommended polarization levels are suitable to prevent localized attack promoted by

15 potential ennoblement induced by bacteria activity.

\section{5. Conclusions}

18 The potential and current distributions in a propeller shaft-stern tube system under cathodic

19 protection by means of two carbon steel galvanic anodes was analysed by means of a finite element

20 model. The model describes the initial polarizing period, when the calcareous deposit is not yet

21 formed.

22 The results of the simulations are in good agreement with experimental data obtained on a full scale

23 propeller system, with stationary shaft in contact with stagnant or flowing natural seawater.

24 The analysis of the system confirms a modest polarization in all operating conditions with aerated

25 water and stationary or rotating shaft. Only in stagnant conditions, without any water renewal, the 26 rapid consumption of oxygen stimulated by cathodic protection leads to an appreciable potential 
1 decrease below the limits of normal protection indicated in the European standards, after tens of

2 hours.

4 References

5 [1] T. Bellezze, R. Fratesi, G. Roventi, Cathodic protection of a ship propeller shaft by impressed

6 current anodes, Metall. Ital., 106(7-8) (2014) 3-7.

7 [2] T. Bellezze, R. Fratesi, G. Roventi, Field tests on the cathodic protection of a ship propeller 8 system, Metall. Ital 105(6) (2013) 1-6.

9 [3] T. Bellezze, G. Roventi, F. R., Localised corrosion and cathodic protection of 17 4PH propeller 10 shafts, Corros. Eng. Sci. Techn. 48(5) (2013) 340-345.

11 [4] EN ISO 15589-2:2014, Petroleum, petrochemical and natural gas industries. Cathodic protection 12 of pipeline transportation systems. Offshore pipelines. (2014).

13 [5] EN 12473, General principles of cathodic protection in sea water. (2000).

14 [6] T. J. Lennox, M. Peterson, Corrosion resistance and cathodic protection of recently developed 15 stainless steel alloys in sea water, Mater. Performance 15(6) (1976) 24-32.

16 [7] N. Ibl, Fundamentals of transport phenomena in electrolytic system - Current distribution, in: E. 17 Yeager, J. O'M. Bockris, B.E. Conway, S. Sarangapani (Eds.), Comprehensive treatise of 18 electrochemistry (vol. 6), Plenum Press, New York, 1983, pp. 1-64 and pp. 239-316.

19 [8] F. Coeuret, A. Storck, Eléments de Génie Electrochimique, Lavoisier Tec. Doc, Paris, 1984.

20 [9] M.E. Orazem, J. M. Esteban, K.J. Kennelle, R.M. Degerstedt, Mathematical Models for Cathodic 21 Protection of an Underground Pipeline with Coating Holidays: 1. Theoretical Development. 22 Corrosion, 53 (1997) 264-272.

23 [10] D.P. Riemer, Orazem, M.E., A Mathematical Model for the Cathodic Protection of Tank 24 Bottoms. Corros Sci., 47 (2005) 849-868. 
1 [11] D.P. Riemer, M.E. Orazem, Modeling Coating Flaws with Non-Linear Polarization Curves for

2 Long Pipelines, in: Modelling of cathodc protection systems. Adey, R. A. ed., WITT Press, 3 Southampton, 2005.

4 [12] M.E. Orazem, J. M. Esteban, K.J. Kennelle, R.M. Degerstedt, Mathematical Models for Cathodic

5 Protection of an Underground Pipeline with Coating Holidays: 2. Case Studies of Parallel Anode CP

$6 \quad$ Systems. Corrosion, 53 (1997) 427-436.

7 [13] K. Nisancioglu, Design techniques in cathodic protection engineering. In Modern Aspects of 8 Electrochemistry. Plenum Press, New York, 1992.

9 [14] J.F. Yan, S.N.R. Pakalapati, T.V. Nguyen, R.E. White, R.B. Griffin. Mathematical Modeling of 10 Cathodic Protection Using the Boundary Element Method with a Nonlinear Polarization Curve. J. 11 Electrochem. Soc., 139 (7) (1992) 1932-1936.

[15] K. Nisancioglu, P.O. Gartland, T. Dahl, E. Sander, Role of Surface Structure and Flow Rate on 13 the Polarization of Cathodically Protected Steel in Seawater. Corrosion, 43 (1987) 710-718.

14 [16] P. Marcassoli, A. Bonetti, L. Lazzari, M. Ormellese, Modeling of potential distribution of subsea 15 pipeline under cathodic protection by finite element method. Mater. Corros., 66 (7) (2015) 619-626.

16 [17] K. Nisancioglu, Predicting the time dependence of polarization on cathodically protected steel 17 in seawater, Corrosion, 43(2) (1987) 100-111.

18 [18] S. L. Carson, M. E. Orazem, Time-dependent polarization behaviour of pipeline-grade steel in 19 low ionic strength environments, J. Appl. Electrochem., 29 (1999) 703-717.

[19] B. Mazza, T. Pastore, P. Pedeferri, G. Rondelli, Electrochemical polarization studies of API 5L

21 grade X65 steel in chloride solution, in: Proceedings of 10th International Congress on Metallic

22 Corrosion (vol. I), Madras 7-11 November 1987, Oxford \& IBH Publishing Co. PVT.LTD., New 23 Delhi, 1987, pp.501-509. 
1 [20] T. Pastore, Distribuzione della corrente e del potenziale su strutture marine ed offshore protette

2 catodicamente - definizione delle condizioni al contorno, PhD Thesis, Politecnico di Milano,

3 Milano, 1989.

4 [21] B. Mazza, T. Pastore, P. Pedeferri, G. Taccani, E. Ferrari, F. Gasparoni, Experimental

5 confirmation of mathematical model for the design of cathodic protection systems, in: Proceedings

6 of 10th International Congress on Metallic Corrosion (vol. I), Madras 7-11 November 1987, Oxford

$7 \quad \&$ IBH Publishing Co. PVT.LTD., New Delhi, 1987, pp.945-954.

8 [22] P. Cicognani, F. Gasparoni, B. Mazza, T. Pastore, Application of the boundary-element

9 method to offshore cathodic protection modelling, J. Electrochem. Soc., 137(6) (1990) 1689-1695.

10 [23] B. Bazzoni, S. Lorenzi, P. Marcassoli, T. Pastore, Current and potential distribution modelling

11 for cathodic protection of tank bottoms., Corrosion, 67(2) (2011) 026001-1-026001-10.

12 [24] M. Cabrini, S. Lorenzi, P. Marcassoli e T. Pastore, Interferenza elettrica in prossimità di giunti 13 isolanti di condotte per il trasporto di acqua sottoposte a protezione catodica, in: Atti $8^{\circ}$ Convegno

14 Nazionale AIMAT, Palermo 27 giungo - 1 luglio, Palermo, 2006, CD-ROM.

15 [25] J. R. Selman, C. W. Tobias, Mass-Transfer Measurements by the Limiting-Current Technique,

16 in: T.B. Drew, G.R. Cokelet, J.W. Hoopes, T. Vermeulen (Eds.), Advances in Chemical

17 Engineering (vol. 10), Academic Press, New York, London, 1978, pp. 211-318.

18 [26] T. Huber, Y. Wang, Effect of Propeller Coating on Cathodic Protection Current Demand: Sea

19 Trial and Modeling Studies, Corrosion, 68(5) (2012) 441-448.

20 [27] W. H. Hartt, 2012 Frank Newman Speller Award: Cathodic protection of offshore structures-

21 History and current status, Corrosion, 68(12) (2012) 1063-1075.

22 [28] A. Neville, A. P. Morizot, Calcareous scales formed by cathodic protection - an assessment of 23 characteristics and kinetics, J. Cryst. Growth, 243 (2002) 490-502.

24 [29] W. Sun, G. Liu, L. Wang, Y. Li, A mathematical model for modelling the formation of 25 calcareous deposits on cathodically protected steel in seawater, Electrochim. Acta, 78 (2012) 597 26608. 
1 [30] R. Johnsen, E. Bardal, Cathodic properties of different stainless steels in natural seawater,

2 Corrosion, 41(5) (1985) 296-302.

3 [31] A. Mollica, A. Trevis, E. Traverso, G. Ventura, G. De Carolis, R. Dellepiane, Cathodic

4 performance of stainless steels in natural seawater as a function of microorganism settlement and

5 temperature, Corrosion, 45(1) (1989) 48-56.

6 [32] M. Faimali, E. Chelossi, G. Pavanello, A. Benedetti, I. Vandecandelaere, P. De Vos, P.

7 Vandamme, A. Mollica, Electrochemical activity and bacterial diversity of natural marine biofilm

8 in laboratory closed-systems, Bioelectrochemistry, 78 (2010) 30-38.

9 [33] I. B. Beech, J. Sunner, Biocorrosion: towards understanding interactions between biofilms and 10 metals, Curr. Opin. Biotech., 15 (2004) 181 - 186.

11 [34] B. J. Little, J. S. Lee, I. R. Ray, The influence of marine biofilms on corrosion: a concise 12 review, Electrochim. Acta, 54 (2008) 2-7.

13 [35] J. Landoulsi, K. El Kirat, C. Richard, D. Feron, S. Pulvin, Enzymatic approach in microbial14 influenced corrosion: a review based on stainless steel in natural seawater, Environ. Sci. Technol., $15 \quad 42(2008) 2233-2242$.

16 [36] C. S. Lin, E. B. Denton, H. Gaskill, G. Putnam, Diffusion -controlled electrode reactions, Ind. 17 Eng. Chem. 43(9) (1951) 2136-2143.

18 [37] M. Eisenberg, C. W. Tobias, C. R. Wilke, Ionic Mass Transfer and Concentration Polarization 19 at Rotating Electrode, J. Electrochem. Soc. 101(6) (1954) 306-320.

20 [38] D. R. Gabe, The rotating cylinder electrode, J. Appl. Electrochem. 4 (1974) 91-108.

21 [39] D. J. Robinson, D. R. Gabe, High speed electrodeposition of copper from conventional 22 sulphate, T. I. Met. Finish. 48 (1970) 35-42.

23 [40] M. Kishinevskii, T. S. Kornienko, Y. E. Guber, Sov. Electrochem. 8 (1972) 617.

24 [41] M. Stern, The electrochemical behaviour, including hydrogen overvoltage, of iron in acid 25 environments, J. Electrochem. Soc. 102(11) (1955) 609-616. 
1 [42] A. Turnbull, M. K. Gardner, Electrochemical polarization studies of BS 4360 50D steel in

$2 \quad 3.5 \% \mathrm{NaCl}$, Corros Sci. 22(7) (1982) 661-673.

3 
Figure Captions

2 Fig. 1 Geometry of the propeller shaft-stern tube system (all dimension are in millimetres). Agi $(i=1, \ldots, 7)$ are the silver/silver chloride reference electrodes; SCE is the saturated calomel reference electrode. The interspace between propeller shaft and stern tube is an annulus with thickness equal to

$524 \mathrm{~mm}$.

7 Fig. 2 Cathodic protection zones for a metal with an active/passive behaviour for the prevention and stop of localized corrosion determined by chlorides attack.

9

Fig. 3 Oxygen limiting current density at $15^{\circ} \mathrm{C}$, in aerated water ( $8 \mathrm{ppm}$ of oxygen), as a function

11 of water /metallic wall relative speed ( $\mathrm{X}$ identify the reference values for the three cases considered 12 in the modelling).

14 Fig. 4 Polarization curve of carbon steel (Eq. 19), used as boundary condition for the calculation of 15 potential and current distributions in the FEM model.

16

17 Fig. 5 Polarization curve of stainless steel (Eq. 20), used as boundary condition for the calculation of potential and current distributions in the FEM model.

19 rate of $10 \mathrm{mV} / \mathrm{min}$ in two different tests.

23

Fig. 7 Potential distribution obtained by means of FEM model with stationary shaft in aerated 
1 Fig. 8 Comparison of the FEM model results with potential values measured [2] on the stern tube

2 with the reference electrodes placed on the opposite generatrix with respect to that relative to the anodes (Fig. 1). Seawater longitudinal flow was $40 \mathrm{~L} / \mathrm{min}$.

5 Fig. 9 Decrease of cathodic current in the propeller system containing stagnant water [2] compared with the results of FEM model with variation of boundary conditions due to the oxygen consumption.

8

Fig. 10 Polarization potential [2] at the location of SCE reference electrode placed in the stern tube (see Fig. 1) with stationary shaft and stagnant water. Comparison with results of FEM model with variation of boundary conditions due to the oxygen consumption.

Fig. 11 Experimental potential distributions as a function of time, measured [2] by the reference electrodes placed along stern tube (see Fig. 1) with stagnant water and stationary shaft. Comparison with results of FEM model with variation of boundary conditions due to the oxygen consumption.

Fig. 12 Potential distribution on the back generatrix of the shaft, with respect to the anodes position (Fig. 1), with rotating shaft or stationary shaft with $40 \mathrm{~L} / \mathrm{min}$ of longitudinal water flow.

Fig. 13 Current density distribution on the back generatrix of the shaft, with respect to the anodes position (Fig. 1), with rotating shaft or stationary shaft with $40 \mathrm{~L} / \mathrm{min}$ of longitudinal water flow.

Fig. 14 Cyclic variation of the polarization potential on the shaft points facing the anodes.

Table 1. Chemical composition of 304 and 17-4PH stainless steels (wt.\%).

Table 2 Symbols and definition of parameters used for the calculation of the oxygen limiting current density. 
2 Table 3 Values of the parameters used for the description of the polarization curves.

3 
Table 1. Chemical composition ${ }^{*}$ of 304 and 17-4PH stainless steels (wt.\%).

\begin{tabular}{cccccccccccc}
\hline Alloy & $\mathbf{C}$ & $\mathbf{S i}$ & $\mathbf{M n}$ & $\mathbf{P}$ & $\mathbf{S}$ & $\mathbf{C r}$ & $\mathbf{M o}$ & $\mathbf{N i}$ & $\mathbf{C u}$ & $\mathbf{N b}$ & $\mathbf{C o}$ \\
\hline $\mathbf{3 0 4}$ & 0.04 & 0.53 & 1.27 & 0.01 & - & 18.13 & 0.33 & 9.24 & 0.20 & 0.01 & 0.12 \\
$\mathbf{1 7 - 4 P H}$ & 0.03 & 0.34 & 0.77 & 0.01 & 0.02 & 15.55 & 0.04 & 5.15 & 3.10 & 0.34 & 0.03 \\
\hline
\end{tabular}

2 "The rest is $\mathrm{Fe}$.

3

4 
2 Table 2 Symbols and definition of parameters used for the calculation of the oxygen limiting current density.

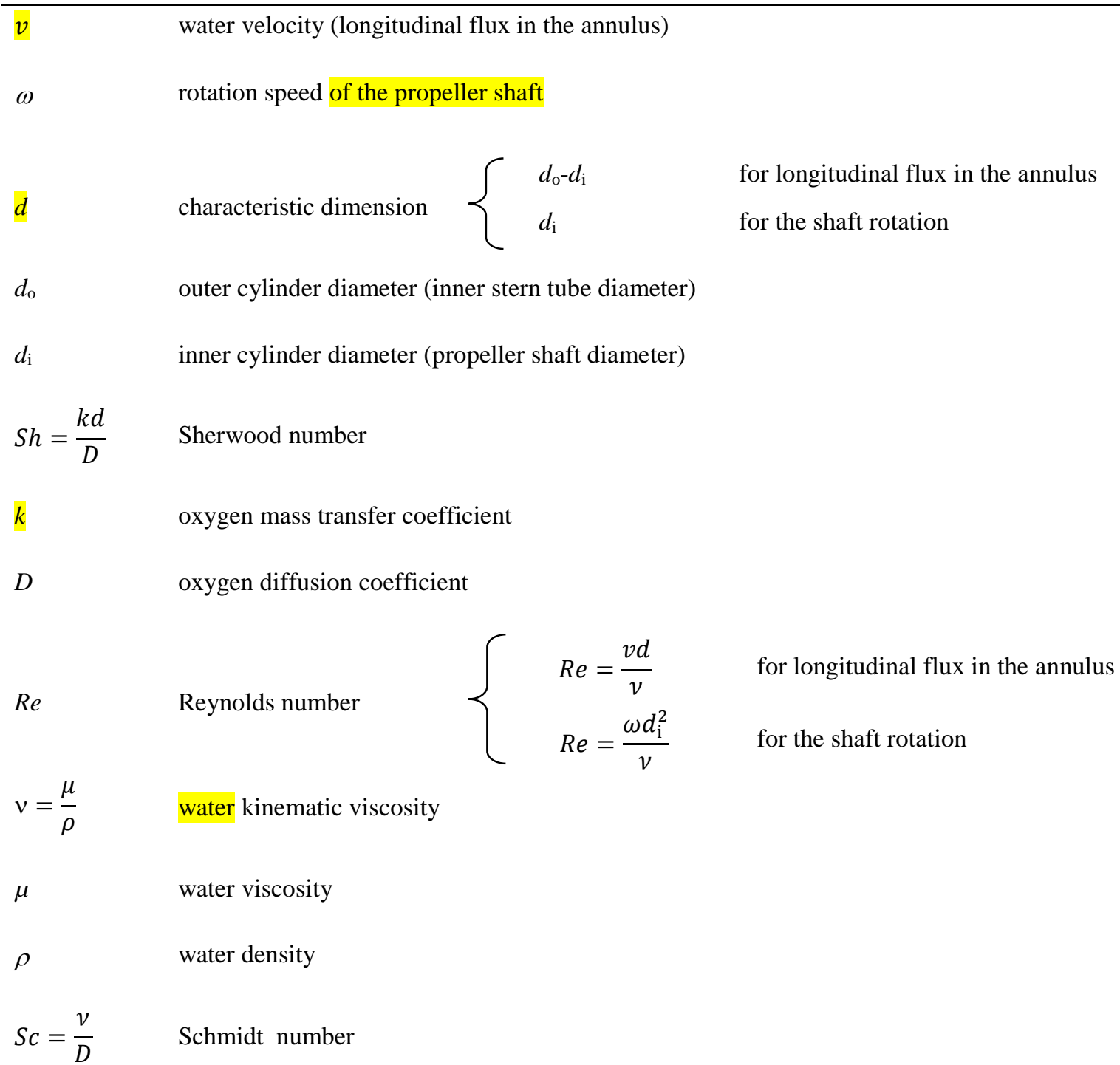


Table 3 Values of the parameters used for the description of the polarization curves.

\begin{tabular}{cll}
\hline$i_{\mathrm{a}, \mathrm{p}}$ & $10^{-3}$ & $\mathrm{~A} / \mathrm{m}^{2}$ \\
$E_{\mathrm{eq}, \mathrm{H}}$ & -0.713 & $\mathrm{~V}$ vs SCE \\
$i_{0, \mathrm{H}}$ & $2 \cdot 10^{-3}$ & $\mathrm{~A} / \mathrm{m}^{2}$ \\
$b_{\mathrm{H}}$ & -0.114 & $\mathrm{~V} / \mathrm{dec}$ \\
$E_{\text {cor,inox }}$ & 0.078 & $\mathrm{SCE}$ \\
$b_{\mathrm{O}_{2}}$ & -0.057 & $\mathrm{~V} / \mathrm{dec}$ \\
$i_{\mathrm{Fe}}$ & $4.4 \cdot 10^{5}$ & $\mathrm{~A} / \mathrm{m}^{2}$ \\
$b_{\mathrm{Fe}}$ & 0.058 & $\mathrm{~V} / \mathrm{dec}$ \\
\hline
\end{tabular}

